\title{
Acalculous Cholecystitis Secondary to Giant Hepatic Abscess. Case Report and Literature Review
}

\author{
Alberto Robles Méndez Hernández ${ }^{1 *}$, Alejandro Vela Torres ${ }^{1}$, Yolik Ramírez-Marín ${ }^{2}, K$ Kelly \\ Milla Hernández ${ }^{1}$, Roberto Jauregui Brechu ${ }^{1}$ \\ ${ }^{l}$ General Surgery Department, Hospital Angeles Metropolitano, Mexico City, Mexico \\ ${ }^{2}$ General Surgery Department, Hospital General La Villa, Surgery Department, Instituto Nacional de Ciencias \\ Médicas y Nutrición Salvador Zubirán, Mexico City, Mexico
}

*Corresponding Author: Alberto Robles Méndez Hernández, General Surgery Service, Hospital Ángeles Metropolitano, Tlacotalpan \#59, Mexico City, Mexico.

\begin{abstract}
Alithiasic cholecystitis (AC) occurs in 5\% of cases of acute cholecystitis, typically in severe patients, treatment of liver abscesses according to size is usually antibiotic therapy and radiological drainage, in refractory cases it may be consider surgical.
\end{abstract}

Clinical case: A 75-year-old male patient with an 11-day history of nonspecific abdominal pain, evidenced by computed axial tomography anhepatic lesion of $134 \mathrm{~mm}$ diameter, was approached laparoscopically in which evidence of cholecystitis and liver abscess was evident and resolved. Results: The patient probably presented a simple hepatic cyst, a lesion from 10 previous years, that was infected with $E$, coli, with subsequent development of $A C$ due to the infection. The resolution of the primary pathologyits complications by laparoscopic was feasible.

Conclusions: The treatment of the primary cause and of the AC is indispensable for the clinical improvement of the patient, the laparoscopic treatment is considered as a safe option to approach the two entities with less morbidity than open surgery.

Keywords: Acute Alithiasic cholecystitis, liver abscess, geriatric

\section{CASE REPORT}

A 75-year-old male patient suffering from abdominal pain 11 days prior to admission, presenting with diffuse abdominal pain, intensity 6/10, a visual analogue scale, exacerbated by the intake of any food, early postprandial fullness, abdominal bloating, and intermittent fever without hourly predominance.

Personal history of arterial hypertension managed with losartan, acute myocardial infarction 9 years ago with reperfusion treatment by balloon catheterization with stenting, chronic smoker, when myocardial infarction protocol, a simple hepatic cyst of 2 $\mathrm{cm}$ was identified. No prior abdominal surgery.

On physical examination, mild dehydration, lung fields suggestive of right pulmonary

ARC Journal of Surgery effusion, cardiac intensity decreased, abdomen globose at the expense of painful abdominal distension pain at deep palpation on epigastrium and right hypochondrium, positive Murphy and Boas sign.

A tomography was performed in which a giant liver lesion was observed in segments IVA and VIII estimated at $134 \mathrm{~mm}$ in diameter (image 1) with a density compatible with a simple cyst. Laboratories: hemoglobin $10.8 \mathrm{~g} / \mathrm{dL}$, platelets $202 \mathrm{x} 10^{3} \mathrm{U} / \mathrm{L}$, leukocytes $10.2 \times 10^{3} \mathrm{U} / \mathrm{L}$, neutrophils $79 \%$. Prothrombin time 17.4 secs, INR 1.55. Activated thromboplastin partial time 46 secs. creatinine $1.55 \mathrm{mg} / \mathrm{dl}$, total protein 5.8 $\mathrm{g} / \mathrm{dL}$, albumin $2.3 \mathrm{~g} / \mathrm{dL}$, globulins $3.4 \mathrm{~g} / \mathrm{dL}$, total bilirubin $0.63 \mathrm{mg} / \mathrm{dL}$, CA $19-9$ antigen 28.1 . $\mathrm{U} / \mathrm{mL}$. 


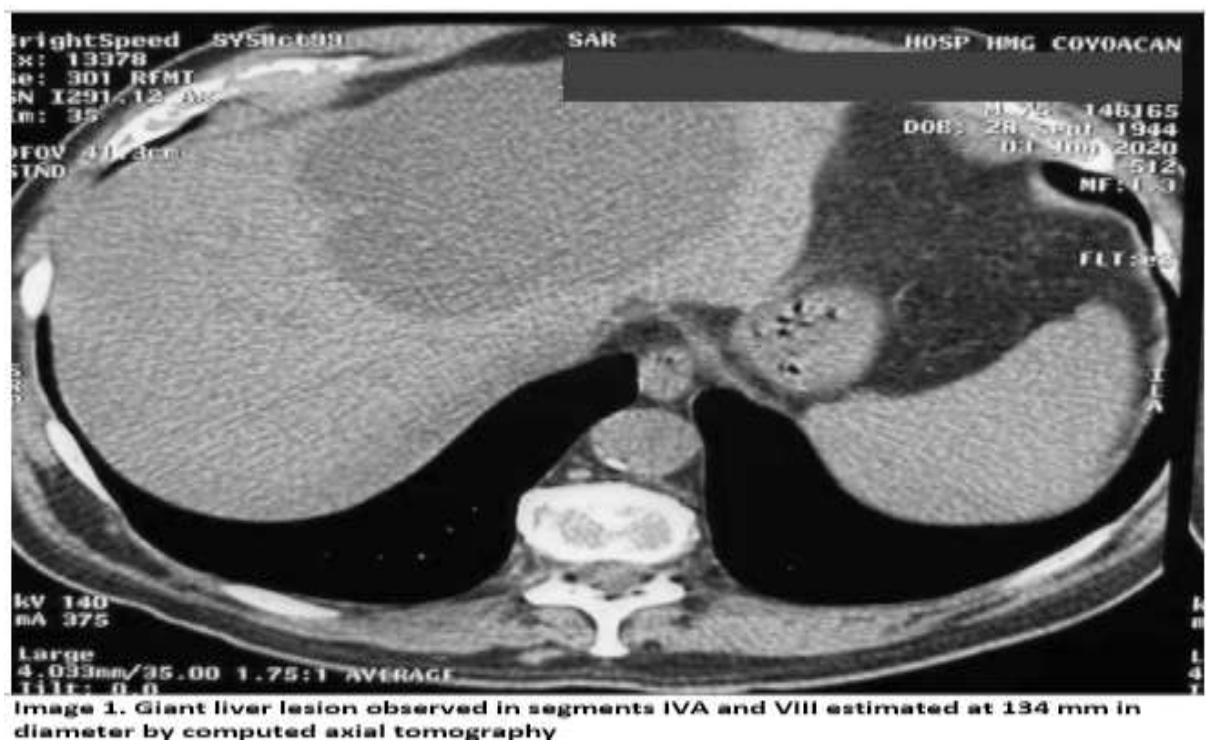

Image1. Giant liver lesion observed in segments IVA and VIII estimated at $134 \mathrm{~mm}$ in diameter by computed axial tomography

It is approached laparoscopically identifying fibrinopurulent peri vesicular and vesicular plastron (image 2), a cholecystectomy is performed, when it is not possible to perform a Strasberg critical vision of safety due to short cystic, an anterograde gallbladder dissection with placement of two Vicryl endoloops on the cystis performed, changes in liver parenchyma are observed (image 3), an incision is made with ultrasonic energy and $950 \mathrm{cc}$ of purulent material are drained. After surgery due to risk factors, it is managed in intensive care, it presents a residual collection of $20 \%$ (image 4) with respect to the initial image and it goes on laparoscopic unroofing and drainage. The culture was positive for Gram negative bacilli E. coli, ESBL negative, sensitive to ertapenem. After this, the patient shows significant improvement and is discharged after 10-day hospitalization. Follow-up is performed at 6 months with adequate evolution.

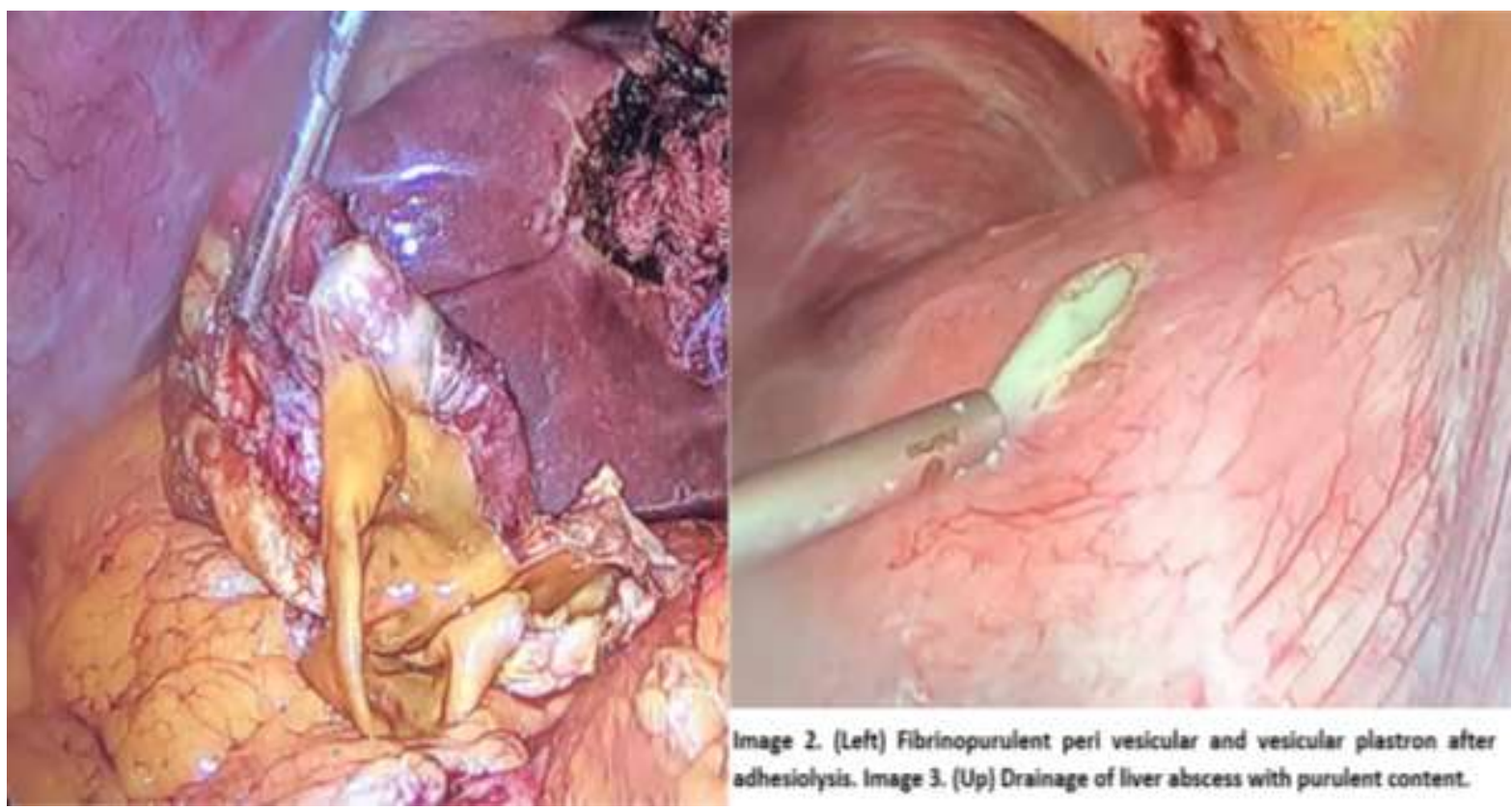

Image2. (Left) Fibrinopurulent peri vesicular plastron after adhesiolysis, Image3. (Up) Drainage of liver abscess with purulent content 


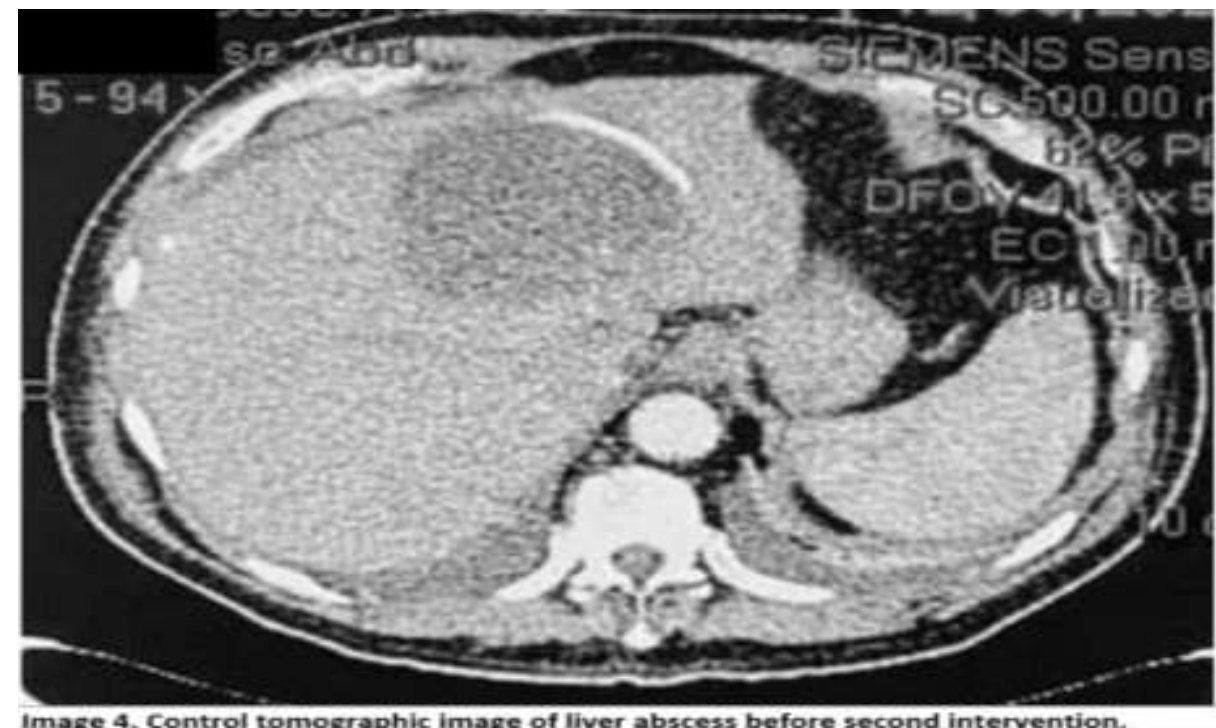

Image4. Control tomographic image of liver abscess before second intervention

\section{DISCUSSION}

Acalculous cholecystitis is the inflammation of the gallbladder without evidence of gallstones; it accounts for the $10 \%$ of all cases of acute cholecystitis; its presentation is insidious and may induce high morbi-mortality.[1] Typically seen in critically ill patients (sepsis, recent trauma, burn injury, surgery, or hemodynamic instability) and on specific infectious conditions.[1-4] Results from gallbladder stasis and ischemia, which then cause a local inflammatory response in the gallbladder wall[5] Characterized by unexplained fever, leukocytosis, hyperamilasemia, high aminotransferases, and may or may not right upper quadrant tenderness with a palpable mass. $[1,5,6]$ Diagnosis of acalculous cholecystitis is based upon a constellation of symptoms and signs in the setting of supportive imaging findings (abdominal ultrasound or contrast abdominal CT), and the exclusion of differential diagnoses. Ultrasound imaging findings include 3.5- to 4-mm (or more) thick wall; sonographic Murphy's sign, pericholecystic fluid/subserosal edema, intramural gas, echogenic bile, hydrops (dimensions greater than $8 \times 5 \mathrm{~cm}$. CT findings include gallbladder wall thickening $(>3 \mathrm{~mm})$, subserosal edema, pericholecystic fluid, intramural gas, gallbladder distention $(>5 \mathrm{~cm})$. [6-8] Management of acalculous cholecystitis includes supportive care with intravenous fluids, pain control, initiation of antibiotics, and definitive therapy with either cholecystectomy or gallbladder drainage. Patients without indications for emergency cholecystectomy (gallbladder necrosis, emphysematous cholecystitis and/or gallbladder perforation), who are critically ill or in poor health, or unfit for general anesthesia should be treated with gallbladder drainage. [6, 9-11]

Liver abscess is a diferential diagnosis of acalculous cholecystitis, there is low evidence of coexistent conditions, the most of them presented as a complication of acalculous cholecystitis. [12-15] When pyogenic liver abscesses develop, it is most commonly following peritonitis due to leakage of intraabdominal bowel contents with subsequent spread to the liver via the portal circulation or in the setting of biliary infection via direct spread. Enteric gram-negative bacilli, particularly Escherichia coli and K. pneumoniae, are generally the most identified pathogens. Clinical manifestations are fever and abdominal pain. $[16,17]$ Other common symptoms include nausea, vomiting, anorexia, weight loss, and malaise. Laboratory abnormalities may include elevated bilirubin and/or liver enzymes. Evaluation of suspected pyogenic liver abscess includes imaging (usually computed tomography or ultrasound), blood cultures, followed by aspiration and culture of the abscess material $[16,18]$. The diagnosis is confirmed in a patient with a liver lesion on imaging that is purulent on aspiration and/or has bacteria identified on Gram stain or culture of the aspirate material or blood.[19,20, 21] Drainage of liver abscess, either surgically (either open or laparoscopic), percutaneously, or via endoscopic retrograde cholangiopancreatography, is standard.[21] A single unilocular abscess, 
percutaneous drainage if $\leq 5 \mathrm{~cm}$ in diameter; if $>5 \mathrm{~cm}$ in diameter, percutaneous catheter drainage rather than needle aspiration.[22] Surgical drainage is appropriate when there is an underlying disease that requires primary surgical management, when there is an inadequate response to catheter drainage, or if the abscess has viscous contents that preclude successful percutaneous drainage. [18, 23]

\section{Conclusion}

The patient probably initially presented with a simple hepatic cyst, a lesion from the previous 10 years, which was infected with $\mathrm{E}$, coli, with subsequent development of AC due to the infection. The treatment allowed the resolution of the primary pathology and its complications.

The treatment of the primary cause and of the $\mathrm{AC}$ is indispensable for the clinical improvement of the patient, the laparoscopic treatment is considered as a safe option to approach the two entities with less morbidity than open surgery

\section{FUNDING AND CONFLICTS OF INTEREST}

None

\section{ETHICAL APPROVAL}

There was no ethics approval required for this case report

\section{CONSENT}

Written informed consent was obtained from the patient for publication of this case report and accompanying images

\section{REFERENCES}

[1] Owen CC, Jain Cholecystitis. Curr

R. Acute Acalculous Gastroenterol. Treat Options doi:10.1007/s11938-005-0001-4

[2] Kalliafas S, Ziegler DW, Flancbaum L, et al. Acute acalculous cholecystitis: incidence, risk factors, diagnosis, and outcome. Am Surg. 1998;64(5):471-475.

[3] Walsh K, Goutos I, Dheansa B. Acute Acalculous Cholecystitis in Burns: A Review. Journal of Burn Care \& Research. 2018;39(5):724-728.

[4] Shapiro MJ, Luchtefeld WB, Kurzweil S, et al. Acute acalculous cholecystitis in the critically ill. Am Surg. 1994;60(5):335-339.

[5] McChesney JA, Northup PG, Bickston SJ. Acute acalculous cholecystitis associated with systemic sepsis and visceral arterial hypoperfusion: a case series and review of pathophysiology. Dig Dis Sci. 2003;
48(10):1960-1967. doi:10.1023/a:10261183204 60

[6] Soria Aledo V, Galindo Iñíguez L, Flores Funes $\mathrm{D}$, et al. Is cholecystectomy the treatment of choice for acute acalculous cholecystitis? A systematic review of the literature. Rev EspEnferm Dig. 2017;109(10):708-718. doi:10.17235/reed.2017.4902/2017

[7] Barie PS, Eachempati SR. Acute acalculous cholecystitis. Gastroenterol Clin North Am. 2010;39(2):343-x. doi:10.1016/j.gtc.2010.02.012

[8] Huffman JL, Schenker S. Acute acalculous cholecystitis: a review. Clin Gastroenterol Hepatol. $2010 ; 8(1): 15-22$. doi:10.1016/j.cgh.2009.08.034

[9] Laméris JS, van Overhagen H. Imaging and intervention in patients with acute right upper quadrant disease. Baillieres Clin Gastroenterol. 1995;9(1):21-36. doi:10.1016/09503528(95) $90068-3$

[10] Ceylan H, Sirikci A, Ozokutan BH, et al. Conservative management of intrahepatic perforation of the gallbladder secondary to acalculous cholecystitis. Eur J Pediatr Surg. 2003;13(5):337-340. doi:10.1055/s-2003-43577

[11] Simorov A, Ranade A, Parcells J, et al. Emergent cholecystostomy is superior to open cholecystectomy in extremely ill patients with acalculous cholecystitis: a large multicenter outcome study. Am J Surg. 2013;206(6):935941. doi:10.1016/j.amjsurg.2013.08.019

[12] Suzuki M, Nabeshima K, Miyazaki M, et al. Churg-Strauss syndrome complicated by colon erosion, acalculous cholecystitis and liver abscesses. World $J \quad$ Gastroenterol. 2005;11(33):5248-5250. doi:10.3748/wjg.v11.i33.5248

[13] Hussain T, Adams M, Ahmed $M$, et al. Intrahepatic perforation of the gallbladder causing liver abscesses: case studies and literature review of a rare complication. Ann $R$ Coll Surg Engl. 2016;98(6):e88-e91. doi:10.1308/rcsann.2016.0115

[14] Liao CY, Tsai CC, Kuo WH, et al. Emphysematous cholecystitis presenting as gas-forming liver abscess and pneumoperitoneum in a dialysis patient: a case report and review of the literature. $B M C$ Nephrol. 2016;17:23. Published 2016 Mar 1. doi:10.1186/s12882-016-0237-3

[15] Reid-Lombardo KM, Khan S, Sclabas G. Hepatic cysts and liver abscess. Surg Clin North Am. 2010;90(4):679-697. doi:10.1016/j.suc.2010.04.004

[16] Johannsen EC, Sifri CD, Madoff LC. Pyogenic liver abscesses. Infect Dis Clin North Am. 2000;14(3):547-vii. doi:10.1016/s0891-5520 (05)70120-3 
[17] Shi SH, Zhai ZL, Zheng SS. Pyogenic Liver Abscess of Biliary Origin: The Existing Problems and Their Strategies. Semin Liver Dis. 2018;38(3):270-283. doi:10.1055/s-00381661363

[18] APA Marrero, Jorge A MD1; Ahn, Joseph MD, FACG2; Reddy, Rajender K MD, FACG3 on behalf of the Practice Parameters Committee of the American College of Gastroenterology ACG Clinical Guideline: The Diagnosis and Management of Focal Liver Lesions, American Journal of Gastroenterology: September 2014 Volume 109 - Issue 9 - p 1328-1347 doi: 10.1038/ajg.2014.213

[19] Mischnik A, Kern WV, Thimme R. PyogenerLeberabszess: Erregerprofil und KonsequenzenfürDiagnostik und Therapie [Pyogenic liver abscess: Changes of Organisms and Consequences for Diagnosis and Therapy]. Dtsch Med Wochenschr. 2017;142(14):1067-1074. doi:10.1055/s-0043100540
[20] Chemaly RF, Hall GS, Keys TF, Procop GW. Microbiology of liver abscesses and the predictive value of abscess gram stain and associated blood cultures. Diagn Microbiol Infect Dis. 2003;46(4):245-248. doi:10.1016/s0732-8893(03)00088-9

[21] Lardière-Deguelte $\mathrm{S}$, Ragot E, Amroun K, et al. Hepatic abscess: Diagnosis and management. J Visc Surg. 2015;152(4):231-243. doi:10.1016/j.jviscsurg.2015.01.013

[22] Zerem E, Hadzic A. Sonographically guided percutaneous catheter drainage versus needle aspiration in the management of pyogenic liver abscess. AJR Am J Roentgenol. 2007;189(3):W138-W142. doi:10.2214/ AJR.07.2173

[23] Tan L, Zhou HJ, Hartman M, et al. Laparoscopic drainage of cryptogenic liver abscess. Surg Endosc. 2013;27(9):3308-3314. doi:10.1007/s00464-013-2910-y

Citation: Alberto Robles Méndez. Hernández, Alejandro Vela Torres, Yolik Ramírez-Marín, Kelly Milla Hernández, Roberto Jauregui Brechu. Acalculous Cholecystitis Secondary to Giant Hepatic Abscess. Case Report and Literature Review. ARC Journal of Surgery. 2020; 6(1):11-15. DOI: https://doi.org/ $10.20431 / 2455-572 X .0601004$.

Copyright: (C) 2020 Authors. This is an open-access article distributed under the terms of the Creative Commons Attribution License, which permits unrestricted use, distribution, and reproduction in any medium, provided the original author and source are credited. 